See Article page 250.

\section{Commentary: One system to rule them all}

\author{
Valerie X. Du, BA, and Shawn S. Groth, MD, MS
}

Over the past 2 decades, the use of large, national clinical registries and administrative datasets has played an increasingly important role in thoracic surgery health services research. ${ }^{1}$ In particular, postoperative complications (or adverse events [AEs]) are important metrics used in quality improvement initiatives and have implications on patient-centered outcomes. ${ }^{2}$ However, the various database entities, such as the Society of Thoracic Surgeons (STS), European Society of Thoracic Surgeons (ESTS), the Esophagectomy Complications Consensus Group, the National Surgical Quality Improvement Program, and the Thoracic Morbidity and Mortality, which was adopted by the Canadian Association of Thoracic Surgeons, have unique definitions for and classifications of AEs. This longstanding problem of a lack of uniform and consistent definitions for AEs contributes to challenges when attempting to compare outcomes and combine information across these datasets.

In this issue of the Journal, Sigler and colleagues ${ }^{3}$ begin to tackle this challenge by presenting a standardized method for AE documentation consisting of a single set of drop-down menu options for classification of AEs. With their proposed modifications, the degree of harmonization with Canadian Association of Thoracic Surgeons increased with the ESTS $(100 \%$ ), STS (from $89 \%$ to $93 \%$ ), Esophagectomy Complications Consensus Group Esophagectomy Complications Consensus Group (from 74\% to $86 \%$ ), and National Surgical Quality Improvement Program (from $73 \%$ to $91 \%$ )

\footnotetext{
From the Division of Thoracic Surgery, Michael E. DeBakey Department of Surgery, Baylor College of Medicine, Houston, Tex.

Disclosures: The authors reported no conflicts of interest.

The Journal policy requires editors and reviewers to disclose conflicts of interest and to decline handling or reviewing manuscripts for which they may have a conflict of interest. The editors and reviewers of this article have no conflicts of interest.

Received for publication May 11, 2021; revisions received May 11, 2021; accepted for publication May 11, 2021; available ahead of print June 3, 2021.

Address for reprints: Shawn S. Groth, MD, MS, Division of Thoracic Surgery, Michael E. DeBakey Department of Surgery, One Baylor Plaza, BCM 390, Houston, TX 77030 (E-mail: Shawn.Groth@bcm.edu).

JTCVS Open 2021;6:257-8

2666-2736

Copyright (c) 2021 The Author(s). Published by Elsevier Inc. on behalf of The American Association for Thoracic Surgery. This is an open access article under the CC BY-NC-ND license (http://creativecommons.org/licenses/by-nc-nd/4.0/).

https://doi.org/10.1016/j.xjon.2021.05.004
}

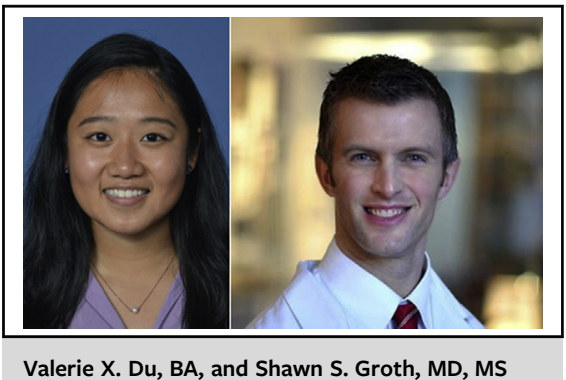

Valerie X. Du, BA, and Shawn S. Groth, MD, MS

\section{CENTRAL MESSAGE \\ Lack of consistent definitions for adverse events contributes to challenges comparing outcomes and combining information across large clinical databases; harmonization of these defini- tions is needed.}

databases. The authors should be congratulated for their efforts to create a framework to unify the definitions of AEs among these data stakeholders. However, it should be recognized that the intent of these effort is not synonymous with linking databases. Currently, if an institution wishes to participate in multiple databases, registrars have to fill in AEs using separate systems, which is expensive and time-consuming. This particular limitation of AE reporting across systems is what the authors begin to address. In other words, the system proposed by Sigler and colleagues ${ }^{3}$ simply makes it easier for a particular institution to simultaneously participate in AE reporting for multiple databases and potentially enables pooling of AE data.

While this is a step in the right direction, limitations and challenges remain. Changes in the definitions of AEs over time create difficulties when performing longitudinal studies within a database. In addition, it should be noted that the authors' proposal for harmonization is neither based on rigorous research nor the collective agreement of experts from multiple groups of stakeholders; it is based on the opinion of 2 authors. While a utopian world for thoracic surgery health services research would include the ability to link all large data sets with ease, there are practical and financial limitations. Finally, when attempting to compare data between datasets, one must recognize that each dataset 
has unique intents, strengths, and limitations and includes particular populations. ${ }^{1}$

Nonetheless, we should recognize that we are an international community of cardiothoracic surgeons who should engage in more collaborative efforts, such as the STSESTS database, and strive to maximize the potential of these large datasets to optimize our outcomes and the quality of care we provide to our patients.

\section{References}

1. Groth SS, Habermann EB, Massarweh NN. United States Administrative Databases and Cancer Registries for Thoracic Surgery Health Services Research. Ann Thorac Surg. 2020;109:636-44.

2. Tevis SE, Kennedy GD. Postoperative complications and implications on patientcentered outcomes. J Surg Res. 2013;181:106-13.

3. Sigler G, Anstee C, Seely A. Harmonization of adverse events monitoring following thoracic surgery: pursuit of a common language and methodology. J Thorac Cardiovasc Surg Open. 2021;162:250-6. 